\section{BMJ Open Respiratory Research}

\title{
Efficacy and safety of high flow nasal oxygen for children with bronchiolitis: systematic review and meta-analysis
}

\author{
Carwyn Dafydd, ${ }^{1}$ Benjamin J Saunders, ${ }^{1}$ Sarah J Kotecha, ${ }^{2}$ \\ Martin O Edwards (iD) ${ }^{1,2}$
}

To cite: Dafydd C,

Saunders BJ, Kotecha SJ, et al. Efficacy and safety of high flow nasal oxygen for children with bronchiolitis: systematic review and metaanalysis. BMJ Open Resp Res 2021;8:e000844. doi:10.1136/ bmjresp-2020-000844

- Additional online supplemental material is published online only. To view, please visit the journal online (http://dx.doi.org/10. 1136/bmjresp-2020-000844).

CD and BJS are joint first authors.

Received 23 November 2020 Accepted 11 July 2021

\section{ABSTRACT}

Background To assess the published evidence to establish the efficacy and safety of high flow oxygen cannula (HFNC) as respiratory support for children up to 24 months of age with bronchiolitis within acute hospital settings.

Methods We searched eight databases up to March 2021. Studies including children up to 24 months of age with a diagnosis of bronchiolitis recruited to an randomised controlled trial were considered in the full meta-analysis. At least one arm of the study must include HFNC as respiratory support and report at least one of the outcomes of interest. Studies were identified and extracted by two reviewers. Data were analysed using Review Manager V.5.4.

Results From 2943 article titles, 308 full articles were screened for inclusion. 23 studies met the inclusion criteria, 15 were included in the metanalyses. Four studies reported on treatment failure rates when comparing HFNC to standard oxygen therapy (SOT). Data suggests HFNC is superior to SOT (OR $0.45,95 \% \mathrm{Cl} 0.36$ to 0.57 ). Four studies reported on treatment failure rates when comparing HFNC to continuous positive airways pressure (CPAP). No significant difference was found between CPAP and HFNC (OR 1.64, 95\% $\mathrm{Cl} 0.96$ to $2.79 ; \mathrm{p}=0.07$ ). Four studies report on adverse outcomes when comparing HFNC to SOT. No significant difference was found between HFNC \& SOT (OR 1.47, 95\% Cl 0.54 to 3.99 ).

Conclusion HFNC is superior to SOT in terms of treatment failure and there is no significant difference between HFNC and CPAP in terms of treatment failure. The results suggest HFNC is safe to use in acute hospital settings.

\section{Check for updates}

\section{(c) Author(s) (or their} employer(s)) 2021. Re-use permitted under CC BY-NC. No commercial re-use. See rights and permissions. Published by BMJ.

${ }^{1}$ Children's Hospital for Wales, University of Wales Hospital, Cardiff, UK

${ }^{2}$ Department of Child Health, Cardiff University, Cardiff, UK

Correspondence to Dr Martin 0 Edwards; Edwardsmo@cardiff.ac.uk

\section{INTRODUCTION}

Viral bronchiolitis is a common condition in young children, causing a huge global burden of disease. Annually, an estimated 3.4million hospitalisations and 199000 deaths worldwide are as a result of respiratory syncytial virus, ${ }^{1}$ which is the most common cause of bronchiolitis. In England, bronchiolitis results in an estimated 46 admissions per 1000 infants under 1 year of age. ${ }^{2}$ A small number of these require intensive care, and bronchiolitis results in an estimated $8 \%$ of all paediatric intensive care unit (PICU)

\section{Key messages}

Given the trend towards increasing use of high flow oxygen cannula (HFNC) in the ward setting and the lack of clear evidence demonstrating its benefit, this review seeks to assess the available published evidence to establish the efficacy and safety of HFNC as respiratory support for children up to 24 months of age with bronchiolitis specifically in an acute hospital setting.

- Our review confirms that HFNC is superior to standard oxygen therapy in terms of treatment failure and length of oxygen therapy and length of hospital stay. It also suggests that HFNC is safe in acute hospital settings.

- It is important for future studies to focus on identifying cohorts of patients with bronchiolitis who will benefit most from HFNC and to provide evidence for the best method of weaning patients off HFNC to further help improve outcomes.

admissions annually ${ }^{2}$ and it has been shown these numbers are rising over the last decade. ${ }^{3}$ Bronchiolitis is one of the most common causes of emergency admissions to PICU.

To date, there has been no demonstration of benefit from beta-agonists, corticosteroids, epinephrine, antibiotics, antivirals or hypertonic saline. ${ }^{4}$ Thus, management recommendations are based on supportive therapy including adequate hydration and where necessary respiratory support, which is reflected in UK guidelines. ${ }^{5}$ Though there are no proven treatments reducing the length of the disease, a key focus of clinical research has been the avoidance of complications, notably admission to PICU (an indication of treatment failure) and possible intubation.

In recent years, there has been increasing interest in using nasal high flow oxygen cannula (HFNC) as a treatment for bronchiolitis. It delivers a heated, humidified, airoxygen mixture through nasal cannula. ${ }^{6}$ It is widely used internationally in the treatment of bronchiolitis, and increasingly has moved 
from the PICU where it was introduced, to the paediatric wards and emergency departments (EDs), ${ }^{47}$ where it is being used as first-line treatment. ${ }^{8}$ Emerging evidence from small observational studies has pointed to the safety of HFNC in the less closely monitored ward setting as opposed to PICU, ${ }^{8-11}$ and others have retrospectively identified potential reasons for failure of ward-based HFNC therapy. ${ }^{12}$

However, this trend towards increasing use of HFNC outside of PICU is despite a lack of clear evidence demonstrating its superiority over conventional treatments, specifically standard oxygen therapy (SOT) and continuous positive airways pressure (CPAP). Given the trend towards increasing use of HFNC in the acute settings and the lack of clear evidence demonstrating its benefit, this review seeks to assess the available published evidence to

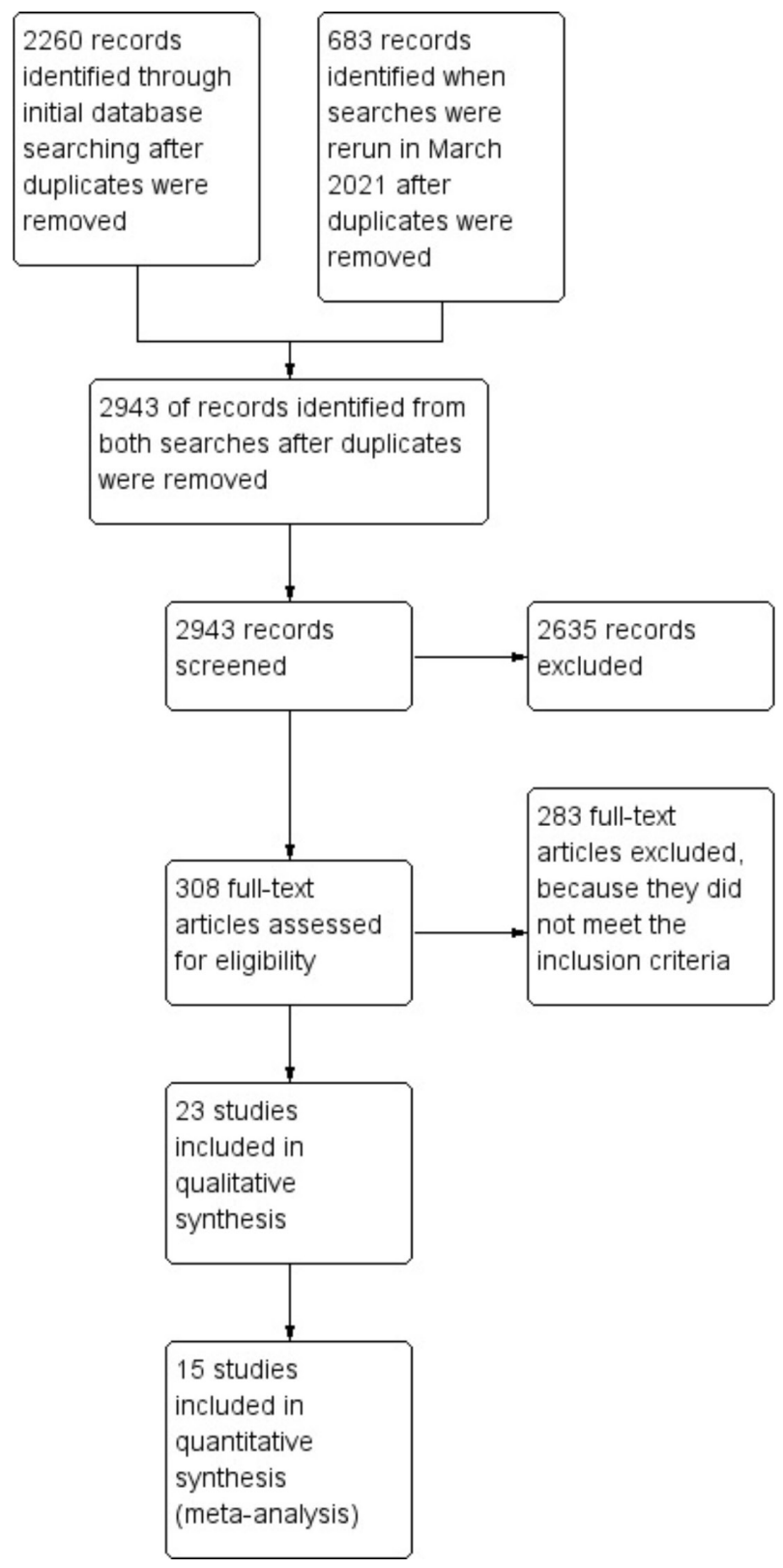

Figure 1 Study selection results. establish the efficacy and safety of HFNC as respiratory support for children up to 24 months of age with bronchiolitis specifically in an acute hospital setting.

This systematic review also collated information on clinical guidance for the use of high flow for patients with bronchiolitis being treated in different acute settings. Published studies have used different protocols for the use of HFNC in clinical trials, but there is no established consensus on appropriate flow rates or when to initiate therapy. ${ }^{46}{ }^{13} \mathrm{Simi}-$ larly weaning protocols differ in clinical trials, and reviews of clinical practice show wider variation. ${ }^{14}$ There is an increasing requirement for protocols for the use of HFNC particularly weaning of HFNC, which may help to reduce hospital length of stay. ${ }^{15} \mathrm{We}$, therefore, aimed to collate any clinical recommendations on the use of HFNC including weaning on paediatric wards from all the studies read as part of the systematic review process.

\section{METHODS \\ Protocol and registration}

The protocol is given in online supplemental and is registered with the PROSPERO International Prospective Register of Systematic Reviews.

\section{Search strategy}

We developed a search strategy (online supplemental) by using key words and medical subject headings terms. The search strategy was run in November 2019 in eight databases: CINAHL, Embase, HMIC Health Management Information Consortium, Medline, Medline in Process, Scopus, OpenSIGLE, Web of Knowledge. The search strategy was rerun in March 2021 in the same eight databases. Articles from all countries but limited to English were included.

\section{Inclusion criteria}

Prospective, randomised or quasi-randomised controlled trials (RCTs) including children up to 24 months of age with a diagnosis of bronchiolitis were considered in the full meta-analysis. At least one arm of the trial must include HFNC as respiratory support. The trial must also report at least one of the outcomes of interest (any death in hospital; death before discharge; any air leak, pneumothorax, or pulmonary interstitial emphysema; failure of therapy within 3 days; failure of therapy within 7 days; nasal trauma, patient comfort; length of stay, length of oxygen supplementation; transfer to PICU; incidence of intubation; length of non-invasive ventilation; respiratory rate, heart rate, arterial carbon dioxide tension, arterial oxygen tension and pulse oxygen saturation or adverse events). Studies from any acute hospital setting; paediatric ED, wards or intensive care were included.

\section{Study selection}

Two reviewers (CD and BJS) independently screened each reference title and abstract (if available) using the inclusion criteria. Complete papers were obtained for those that met 


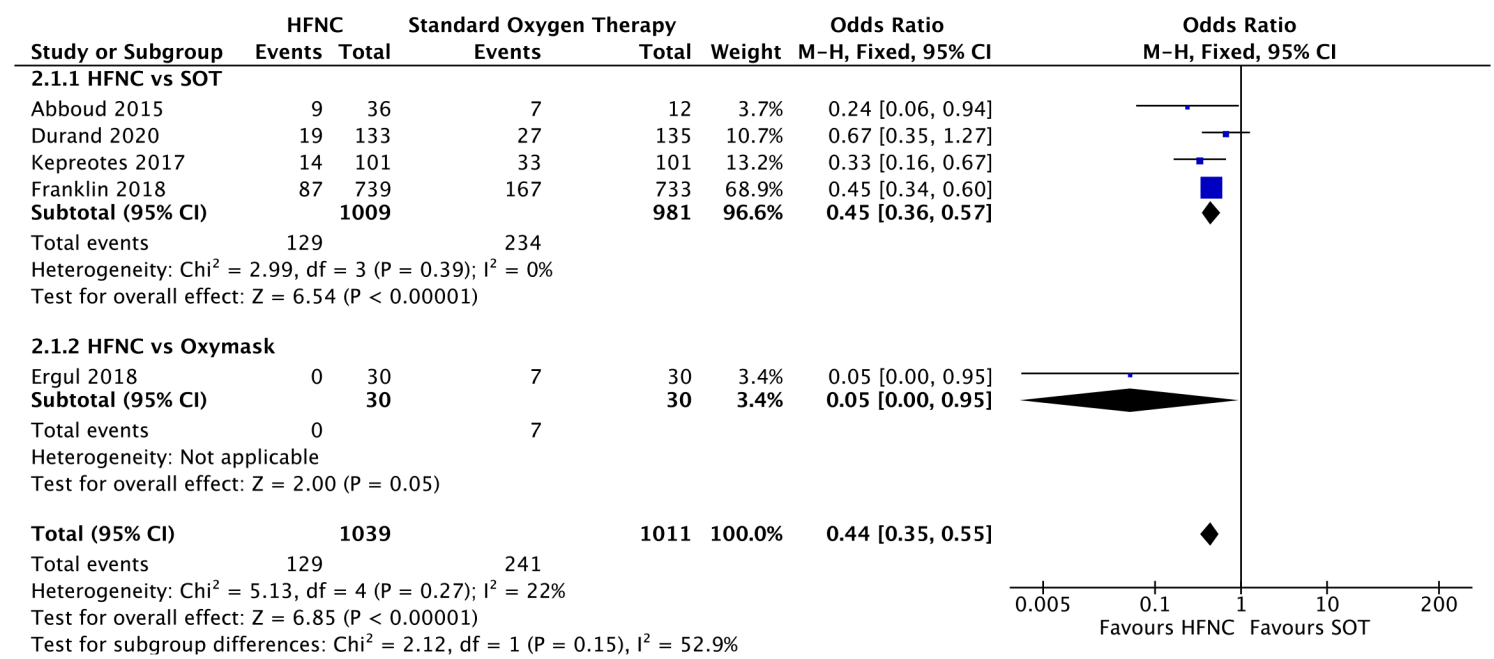

Figure 2 Comparison of high-flow nasal cannula (HFNC) versus SOT and Oxymask: treatment failure. M-H, MantelHaenszel; SOT, standard oxygen therapy.

the inclusion criteria. The reviewers then screened the full paper using the inclusion criteria. Papers that did not meet the inclusion criteria were excluded. Where there was disagreement on inclusion a third reviewer (MOE) applied the inclusion criteria and made a decision.

\section{Data collection process}

Data were collected using a data extraction form which is given in online supplemental. Data extraction was performed by one reviewer (SJK). A second reviewer (CD or BJS) independently data extracted from a sample of papers to cross-check for accuracy.

\section{Assessment of study quality}

Assessment of bias was conducted using a domain-based flowsheet given in online supplemental by one reviewer (CD or BJS). We specifically looked at selection bias, performance bias, attrition bias, reporting bias, any other form of bias specific to the study design. Minimum score was 6 (low quality) and maximum 20 (high quality).

\section{Outcomes}

The primary outcomes were failure of treatment of HFNC or SOT in ward or paediatric ED settings and rates of admission to PICU. Failure of therapy varied between studies but was generally considered as need to escalate respiratory support to HFNC from SOT or CPAP from HFNC or intubation from SOT, HFNC or CPAP. Data on several secondary outcomes were collected including intubation rates, and respiratory outcomes (respiratory complications such as pneumothorax, mode, and length of respiratory support and length of stay in hospital). As part of a subgroup analysis, we analysed studies that were conducted on paediatric wards or ED only.

\section{Statistical analysis}

Statistical analysis was performed using Review Manager (RevMan V.5.4). Dichotomous data (mortality, air leak, nasal trauma, incidence of intubation, escalation of care) was calculated using risk ratio. Continuous outcomes (length of treatment with supplemental oxygen, length of non-invasive ventilation, length of stay, physiological parameters, patient comfort score) was calculated using mean difference, or standardised mean difference if the unit of measurement is different from study to study. $95 \%$ CIs were used and a $p$ value of $<0.05$ considered significant. Heterogenicity ( $\mathrm{I}^{2}$ among studies were calculated and considered significant if $>50 \%$. Fixed-effects model was used if there is a low chance of heterogenicity $(<49 \%)$, and a random-effects model used for a high chance of heterogenicity. The method of Wan et al was

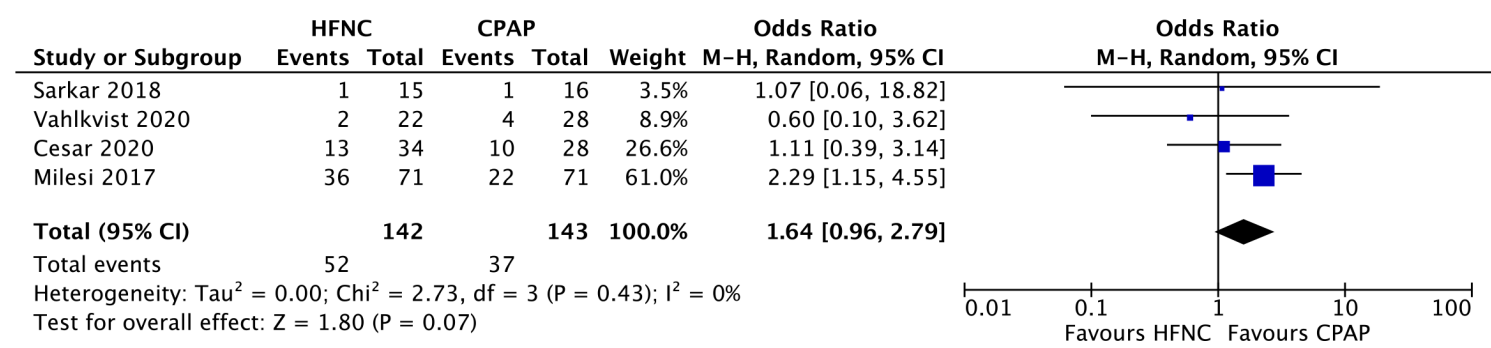

Figure 3 Comparison of high-flow nasal cannula (HFNC) versus CPAP outcome: treatment failure. CPAP, continuous positive airways pressure; $\mathrm{M}-\mathrm{H}$, Mantel-Haenszel. 
used to convert the medians to means where possible for included articles ${ }^{16-19}$ reporting median values. ${ }^{20}$

\section{RESULTS}

\section{Literature search}

The search strategy identified 2943 titles and abstracts after duplicates were deleted; 308 full articles were screened, and 23 met the inclusion criteria. ${ }^{16-19} 21-398$ were excluded from the meta-analyses as they had insufficient data ${ }^{28-32} 34-36$ and 15 were included in the metaanalyses (figure 1). ${ }^{16-19}$ 21-27 $3337-39$

\section{Characteristics of included studies}

Characteristics of the included studies are given in online supplemental table 1. Studies were published between 2012 and 2021 inclusive. The included children were aged up to 24 months and studies were carried out in different countries.

\section{Meta-analysis of outcomes}

Four studies reported on treatment failure rates (definition of failure included in online supplemental table 1) when comparing HFNC to SOT ${ }^{18} 212237$ with another one study comparing HFNC to oxygen delivered through oxymasks (a face mask for delivering oxygen that uses a 'diffuser"to concentrate and direct oxygen toward the nose and mouth, thus delivering high concentrations of oxygen at low flow). ${ }^{17}$ The pooled data suggest that HFNC is superior to SOT therapy in avoiding treatment failure (OR $0.44,95 \%$ CI 0.35 to $0.55, \mathrm{p}<0.00001$ ) (figure 2 ).

Four studies reported on treatment failure rates when comparing HFNC to CPAP. ${ }^{16} 23249$ The pooled data show no significant difference between CPAP and HFNC (OR $1.64,95 \%$ CI 0.96 to $2.79 ; \mathrm{p}=0.07$ ) (figure 3 ). Heterogeneity was insignificant $\left(\mathrm{I}^{2}=0 \%\right)$. Total number of patients included across the three studies were low (142 in HFNC and 143 in CPAP groups). To note the largest study by Milési et al showed a significant difference (OR 2.29, $95 \%$ CI 1.15 to 4.55$){ }^{23}$

Seven studies reported on rates of admission to PICU when comparing HFNC to SOT. ${ }^{182225-273738}$ There was no significant difference in the pooled data favouring either HFNC or SOT (OR $1.10,95 \%$ CI 0.84 to $1.42, \mathrm{p}=0.49$ ) (figure 4-2.2.1). If another study ${ }^{19}$ which compared HFNC to SOT combined with hypertonic saline is included there is a similar null result (OR 1.11, 95\% CI 0.86 to $1.43, \mathrm{p}=0.44$ ).

Four studies reported on rates of intubation when comparing HFNC to SOT. ${ }^{21} 22337$ The pooled data do not suggest any significant difference between HFNC and SOT (OR 0.94, 95\% CI 0.42 to 2.13, $\mathrm{p}=0.17$ ) (online supplemental figure 1). The statistics remain identical if the study including oxymasks is included due to no intubations in either arm of their study.

Three papers report on the rates of intubation when comparing HFNC to CPAP ${ }^{162324}$ and suggest no significant difference (OR 1.78, 95\% CI 0.68 to $4.69, \mathrm{p}=0.92$ ) (online supplemental figure 2).

Six papers compared total length of stay (in days) between HFNC and SOT 182227333738 and the pool data showed a significant difference in favour of HFNC (MD $-0.17,95 \%$ CI 0.33 to $-0.01, \mathrm{p}<0.00001$ ) (figure $5-2.3 .1$ ). The difference increases when the studies on SOT+ oxymask $^{17}$ and SOT + hypertonic saline ${ }^{19}$ are included (MD $-0.33,95 \%$ CI -0.48 to $-0.18, \mathrm{p}=<0.00001$ ) (figure 5 ). Heterogeneity was significant $\left(\mathrm{I}^{2}=93.4 \%\right)$.

Six papers compare total oxygen therapy (in days) between HFNC and SOT, with an additional paper comparing HFNC and SOT+oxymask. ${ }^{17} 182227333738$ The pooled data favours HFNC (MD $-0.08,95 \% \mathrm{CI}-0.11$ to $-0.04, \mathrm{p}<0.00001$ ) (online supplemental figure 3 ).

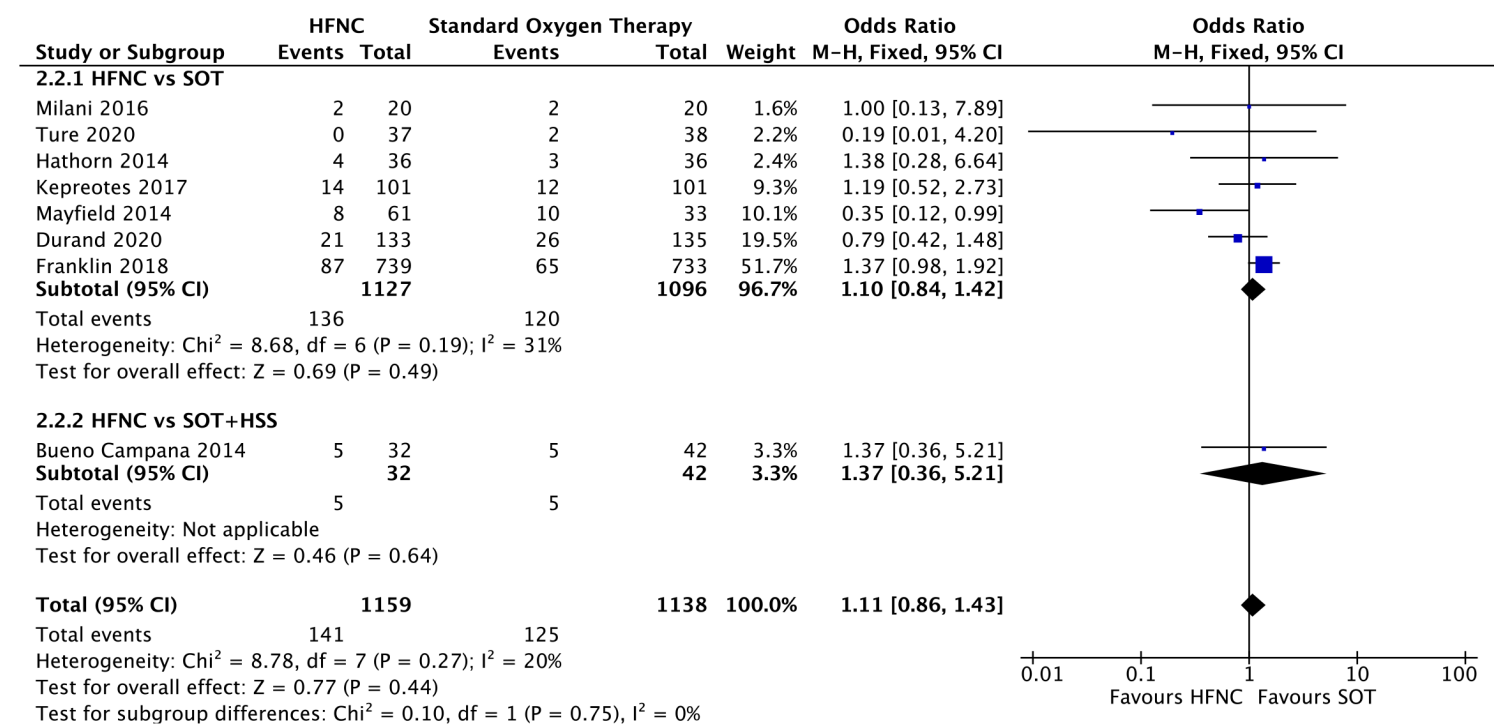

Figure 4 Comparison of high-flow nasal cannula (HFNC) versus SOT and HSS outcome: rates of admission to PICU. M-H, Mantel-Haenszel; PICU, paediatric intensive care unit; SOT, standard oxygen therapy. 


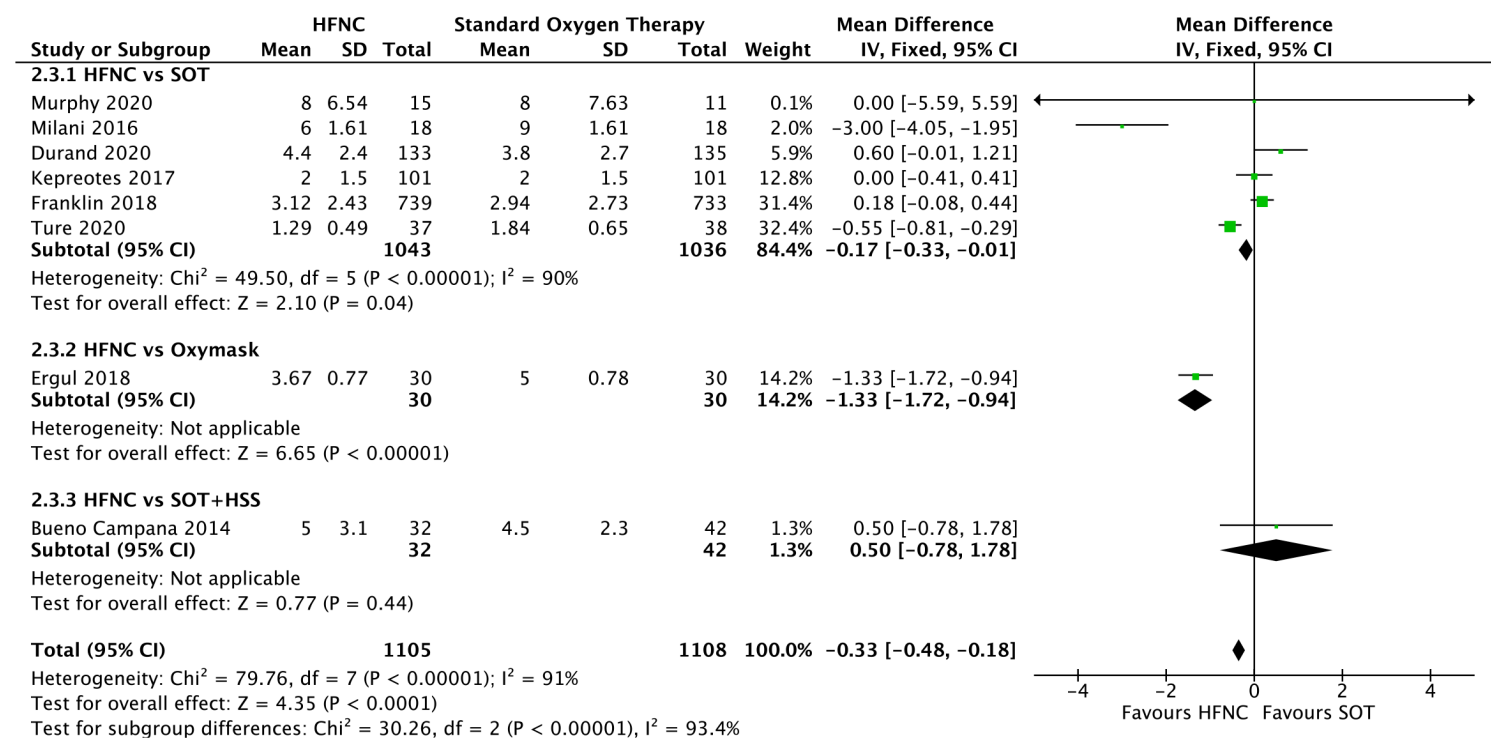

Figure 5 Comparison of high-flow nasal cannula (HFNC) versus SOT, Oxymask and HSS outcome: total length of stay days. SOT, standard oxygen therapy.

Four papers are included in the meta-analysis comparing adverse effects between HFNC and SOT. ${ }^{1822} 2537$ There is no significant difference between HFNC and SOT (OR $1.47,95 \%$ CI 0.54 to $3.99, \mathrm{p}=0.45$ ) (figure 6 ). Two studies reported no adverse effects in either group. ${ }^{19} 25$ Unfortunately, this means they cannot be included in the meta-analysis but support the safety profile of HFNC. Two papers compare rates of nasal trauma between HFNC and CPAP. ${ }^{23}{ }^{24}$ HFNC causes less nasal trauma than CPAP (OR $0.20,95 \%$ CI 0.06 to $0.63, p=0.006$ ) (online supplemental figure 4). There is no significant heterogeneity $\left(I^{2}=0 \%\right)$.

\section{Subgroup analysis}

We analysed studies that were based on general paediatric wards including ED and excluding those conducted in PICU. All these studies compared HFNC to SOT (including SOT with hypertonic saline). ${ }^{18} 2227333738$
HFNC continues to be superior to SOT with regards to treatment failure rates (OR $0.46,95 \%$ CI 0.36 to 0.59 , $\mathrm{p}<0.00001$ ) with heterogeneity being $6 \%$ (figure 7 ). The data for duration of oxygen therapy remains significant, favouring HFNC (MD $-0.07,95 \%$ CI -0.11 to -0.03 , $\mathrm{p}=0.0002$ ) (figure 8 ). The data for adverse events do not differ to the original analysis.

\section{QUALITY}

Quality scores ranged from 9 to 17 out of 20 and the score for each study is given in online supplemental table 1. Only one study scored less than 10 and so maybe considered lower quality compared with the other studies included.

\section{GUIDELINES}

No paper in our systematic review includes guidelines on the use of HFNC in bronchiolitis. There are differences

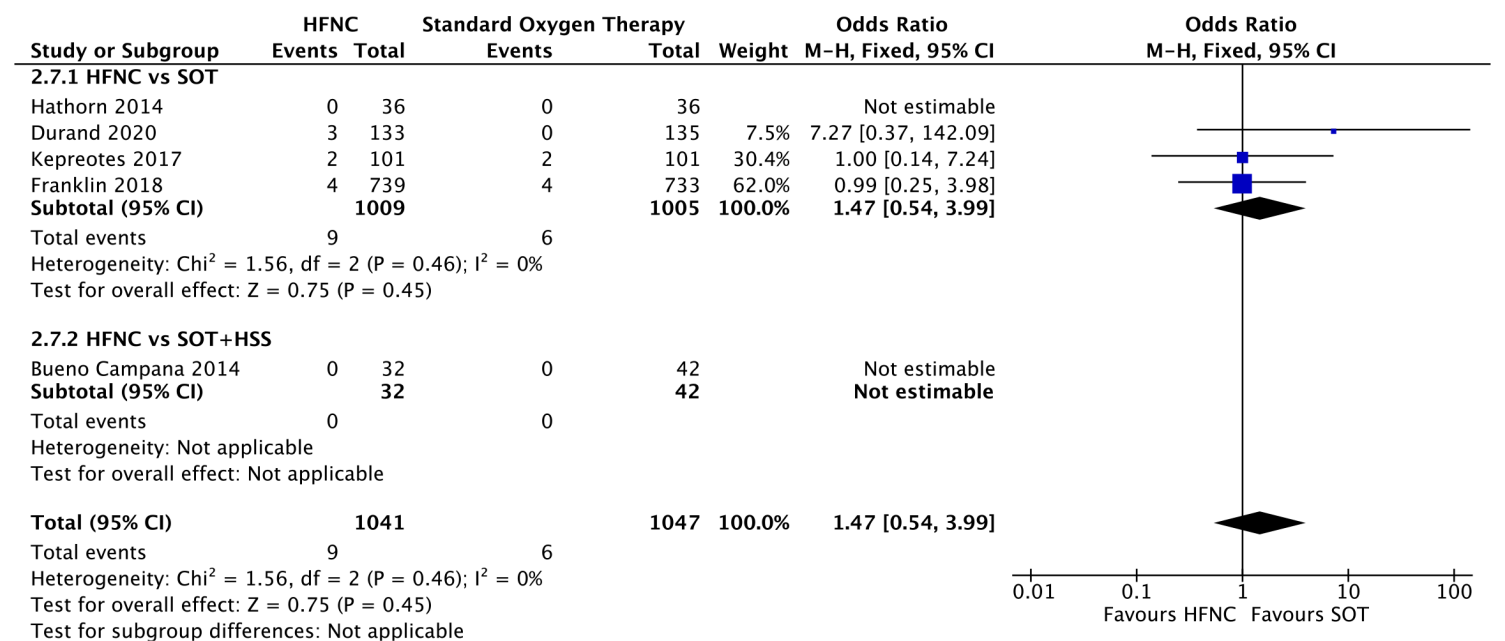

Figure 6 Comparison of high-flow nasal cannula (HFNC) versus SOT and HSS outcome: adverse effects. M-H, MantelHaenszel; SOT, standard oxygen therapy. 


\begin{tabular}{|c|c|c|c|c|c|c|c|c|c|c|}
\hline \multirow{2}{*}{$\frac{\text { Study or Subgroup }}{2.1 .1 \text { HFNC vs SOT }}$} & \multicolumn{2}{|c|}{ HFNC } & \multicolumn{2}{|c|}{ Standard Oxygen Therapy } & \multirow[t]{2}{*}{ Weight } & \multirow[t]{2}{*}{$\begin{array}{c}\text { Odds Ratio } \\
\text { M-H, Fixed, } 95 \% \mathrm{CI}\end{array}$} & \multicolumn{4}{|c|}{$\begin{array}{c}\text { Odds Ratio } \\
\text { M-H, Fixed, } 95 \% \mathrm{Cl}\end{array}$} \\
\hline & & & & & & & & & & \\
\hline Durand 2020 & 19 & 133 & 27 & 135 & $11.5 \%$ & $0.67[0.35,1.27]$ & & $\longrightarrow$ & & \\
\hline Kepreotes 2017 & 14 & 101 & 33 & 101 & $14.3 \%$ & $0.33[0.16,0.67]$ & & $\longrightarrow$ & & \\
\hline $\begin{array}{l}\text { Franklin } 2018 \\
\text { Subtotal }(95 \% \mathrm{CI})\end{array}$ & 87 & $\begin{array}{l}739 \\
973\end{array}$ & 167 & $\begin{array}{l}733 \\
969\end{array}$ & $\begin{array}{r}74.2 \% \\
100.0 \%\end{array}$ & $\begin{array}{l}0.45[0.34,0.60] \\
\mathbf{0 . 4 6}[0.36,0.59]\end{array}$ & & & & \\
\hline $\begin{array}{l}\text { Total events } \\
\text { Heterogeneity: } \mathrm{Chi}^{2} \\
\text { Test for overall effec }\end{array}$ & $\begin{array}{r}120 \\
2.13, d f \\
Z=6.2\end{array}$ & $\begin{array}{l}=2(P \\
9(P<0\end{array}$ & $\begin{array}{l}227 \\
=0.34) ; I^{2}=6 \% \\
.00001)\end{array}$ & & & & & & & \\
\hline Total $(95 \% \mathrm{Cl})$ & & 973 & & 969 & $100.0 \%$ & $0.46[0.36,0.59]$ & & $\diamond$ & & \\
\hline Total events & 120 & & 227 & & & & & & & \\
\hline $\begin{array}{l}\text { Heterogeneity: } \mathrm{Chi}^{2} \\
\text { Test for overall effec } \\
\text { Test for subgroup di }\end{array}$ & $\begin{array}{l}2.13, \mathrm{df} \\
\mathrm{Z}=6.2 \\
\text { ferences: }\end{array}$ & $\begin{array}{l}=2(\mathrm{P} \\
9(\mathrm{P}<0 \\
\text { Not ap }\end{array}$ & $\begin{array}{l}=0.34) ;\left.\right|^{2}=6 \% \\
.00001) \\
\text { plicable }\end{array}$ & & & & $\frac{1}{0.005}$ & $\begin{array}{cc}1 \\
0.1 & 1 \\
\text { Favours HFNC }\end{array}$ & \begin{tabular}{|cc}
1 & 10 \\
Favours SOT
\end{tabular} & 200 \\
\hline
\end{tabular}

Figure 7 Comparison of high-flow nasal cannula (HFNC) versus SOT on the wards: treatment failure. M-H, Mantel-Haenszel; SOT, standard oxygen therapy.

between studies on when HFNC should be initiated, which cohort of patients to use HFNC on, what flow rates to use and how to wean off the HFNC.

\section{DISCUSSION}

We believe our systematic review and meta-analysis is the most comprehensive and up to date, including a wider range of studies and having searched a greater number of database than other recent systematic reviews on HFNC in bronchiolitis. ${ }^{64041}$ This resulted in the inclusion of 23 studies, more than double other recent systematic reviews with 15 studies included in the meta-analysis. ${ }^{6}{ }^{40}$ This is a strength of this systematic review and meta-analysis, which further helps to support the evidence basis to use HFNC in bronchiolitis in acute hospital settings other than PICU.

HFNC has become increasingly popular over the last decade and its use has moved from the traditional PICU/ HDU setting to the general paediatric ward. ${ }^{84}$ This led to the reporting of the efficacy and safety of HFNC as a form of respiratory support for children with bronchiolitis, although mainly in the PICU/HDU setting. A 2019 systematic review and meta-analysis ${ }^{5}$ found nine RCTs comparing HFNC to CPAP or SOT and found no demonstrable difference in length of stay, length of supplemental oxygen supplementation or transfer to PICU. There was a demonstration of superiority of HFNC over SOT in terms of treatment failure, but inferiority compared with CPAP. The emerging consensus is for HFNC as a rescue therapy for those children not supported by SOT, ${ }^{11}$ but new trials have been published since. Our review confirms that HFNC is superior to SOT in terms of treatment failure. It also importantly demonstrated a trend towards reduced length of stay and oxygen therapy in favour of HFNC compared with SOT. Interestingly the review also showed no difference between CPAP and HFNC in terms of treatment failure or intubation rates, but there were low numbers in all three studies included and only one study showed a significant difference. ${ }^{23}$

Treatment failure and rates of admission to PICU have often been reported as the primary outcomes in studies looking at the effects of HFNC in bronchiolitis and are the outcomes of interest for this review. We report that HFNC was superior to SOT for treatment failure, length of stay and length of oxygen therapy but showed no difference for PICU admissions nor rates of intubation.

However, the definition of treatment failure was not homogenous. In most studies who included treatment failure as an outcome there was an option for individual clinicians to independently decide that participants had failed a particular therapy, in addition to objective markers such as worsening of physiological parameters. This potentially creates significant bias and is a limitation of this systematic review and meta-analysis. As with other systematic reviews we were limited by the data reported in the included studies, and also how the data were reported.

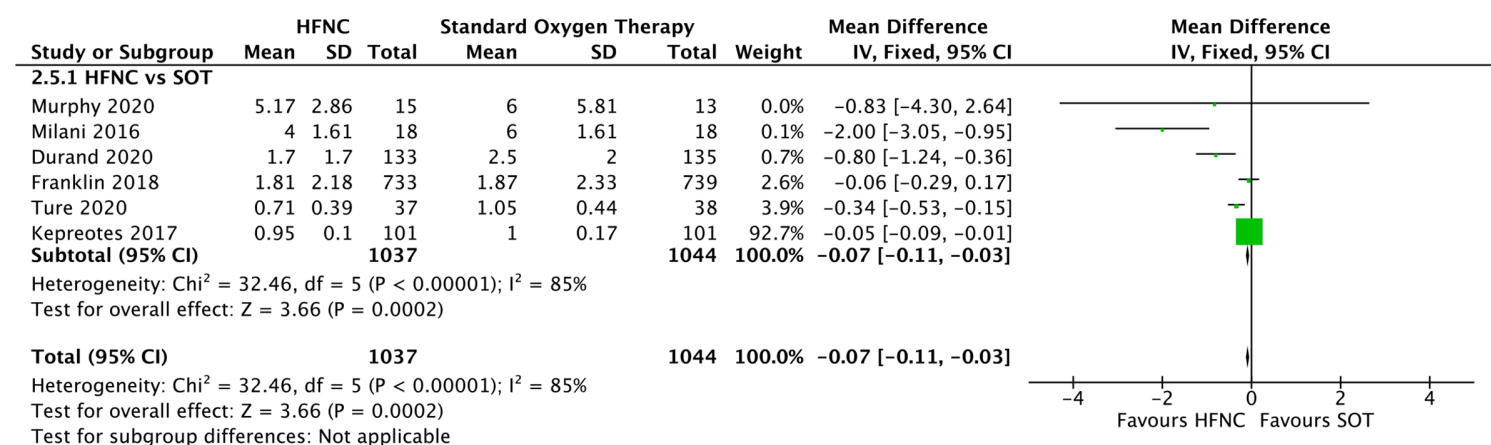

Figure 8 Comparison of high-flow nasal cannula (HFNC) versus SOT on the wards: total $\mathrm{O}_{2}$ therapy in days. SOT, standard oxygen therapy. 
Treatment failure as a subjective outcome therefore does not provide hard evidence to support the use of HFNC over SOT where there is no correlation outcomes which directly affect patient outcome and cost, such as PICU admission or length of stay, and it limits the validity of treatment failure as a research outcome. Many of the studies included in this systemic review also focused on other physiological outcomes such as respiratory rate or heart rate, but these are also not useful for determining if HFNC is beneficial for patients. It is therefore recommended that a scoring system for bronchiolitis is established that can then be used to provide consistency in research studies.

The rates of admission to PICU were not significantly different between HFNC and SOT. Importantly however, not all studies differentiated between HDU and PICU level care. It is for this reason that rates of intubation are likely to reflect more accurately the need for PICU as opposed to HDU care, and there was no difference in the rates of intubation between HFNC and SOT, or HFNC and CPAP. This implies that there may be a large degree of subjectivity involved in escalating patients from paediatric wards to PICU or HDU level care and in terms of respiratory support. If we consider avoiding PICU admission to be a major goal of therapy for bronchiolitis, especially in terms of cost, the potential decision to admit is a very important one. Research assessing this outcome should consider using a scoring system to provide consistency in clinical practise.

Our sub-analysis was to establish the safety of HFNC on general paediatric wards. The results show HFNC superiority over SOT in treatment failure rates and duration of oxygen therapy, no difference in intubation rates (HFNC vs SOT; HFNC vs CPAP), and the lack of adverse events support its safety profile and use on the general paediatric ward. So HFNC is safe to use but how and when should it be used.

Surprisingly our systematic review is the first to demonstrate a difference for total length of stay between HFNC and SOT, which has the potential to be cost saving. This is important as various factors can influence the total length of stay. We argue that the most significant influence is individual studies' guidance on commencing HFNC, the flow rates used, and the protocol for weaning-if any. Clearer guidance is required on the use of high flow to optimise its use, and further evidence is needed to establish weaning protocols. There is also a need to understand if any specific method of weaning leads to a reduction in length of stay. This has the potential to lead to even greater differences in the total length of stay and possible cost benefits.

Studies have attempted to identify the optimal flow rate, including three studies in our review. It is difficult to draw any substantial conclusion due to the variety of flow rates used. However, higher flow rates seem to be more favourable. It is not possible to provide clear guidance from the available evidence on how to start HFNC. However, the majority of studies recommended using
HFNC as a rescue therapy and starting on a flow rate of $2 \mathrm{~L} / \mathrm{kg} / \mathrm{min}$.

HFNC devices are relatively expensive, with the added cost of consumables for every new patient. Cost-effective analysis was not part of our inclusion criteria and only one study details their health economic estimates. ${ }^{18}$ Their results of less treatment failure of the HFNC group led to their suggestion that HFNC can be cost effective due to reduced PICU admissions. A recent, within study analysis, of one of the included studies found that there was only a small chance of cost savings with early HFNC use compared with rescue HFNC. ${ }^{43} 44$ The studies that looked at the use of high flow as rescue therapy for patients deteriorating on SOT found that it was effective in $61 \%$ and $62.5 \%$ of cases. ${ }^{18} 43$ This suggests that HFNC's best role might not be as routine use, but as rescue therapy for those failing on SOT. It has also been shown to be safe and there is no difference in adverse events.

\section{CONCLUSION}

It is important for future studies to focus on identifying cohorts of patients with bronchiolitis who will benefit most from HFNC and to provide evidence for the best method of weaning patients off HFNC. By identifying the ideal cohort of patients and potentially speeding up the weaning process, this could lead to improved outcomes when using HFNC compared with SOT. However, these studies will only be possible if a standardised bronchiolitis scoring system is developed and introduced for routine clinical practise and research use.

Contributors All authors were involved in the design, conduct and analysis of this systematic review and meta-analysis. CD wrote the draft paper and all authors contributed to revising and drafting the final manuscript.

Funding The authors have not declared a specific grant for this research from any funding agency in the public, commercial or not-for-profit sectors.

Competing interests None declared.

Patient consent for publication Not required.

Provenance and peer review Not commissioned; externally peer reviewed.

Data availability statement All data relevant to the study are included in the article or uploaded as online supplemental information. All data relevant to the study are included with the article.

Supplemental material This content has been supplied by the author(s). It has not been vetted by BMJ Publishing Group Limited (BMJ) and may not have been peer-reviewed. Any opinions or recommendations discussed are solely those of the author(s) and are not endorsed by BMJ. BMJ disclaims all liability and responsibility arising from any reliance placed on the content. Where the content includes any translated material, BMJ does not warrant the accuracy and reliability of the translations (including but not limited to local regulations, clinical guidelines, terminology, drug names and drug dosages), and is not responsible for any error and/or omissions arising from translation and adaptation or otherwise.

Open access This is an open access article distributed in accordance with the Creative Commons Attribution Non Commercial (CC BY-NC 4.0) license, which permits others to distribute, remix, adapt, build upon this work non-commercially, and license their derivative works on different terms, provided the original work is properly cited, appropriate credit is given, any changes made indicated, and the use is non-commercial. See: http://creativecommons.org/licenses/by-nc/4.0/.

Martin 0 Edwards http://orcid.org/0000-0002-7243-7039 


\section{REFERENCES}

1 Florin TA, Plint AC, Zorc JJ. Viral bronchiolitis. Lancet 2017;389:211-24.

2 Green CA, Yeates D, Goldacre A, et al. Admission to hospital for bronchiolitis in England: trends over five decades, geographical variation and association with perinatal characteristics and subsequent asthma. Arch Dis Child 2016;101:140-6.

3 Schlapbach LJ, Straney L, Gelbart B, et al. Burden of disease and change in practice in critically ill infants with bronchiolitis. Eur Respir $J$ 2017;49. doi:10.1183/13993003.01648-2016. [Epub ahead of print: 0106 2017].

4 O'Brien S, Craig S, Babl FE, et al. 'Rational use of high-flow therapy in infants with bronchiolitis. what do the latest trials tell us?' a paediatric research in emergency departments international collaborative perspective. J Paediatr Child Health 2019:55:746-52.

5 National Institute for Health and Clinical Excellence (NICE). Bronchiolitis in children: diagnosis and management, 2015. Available: https://www.nice.org.uk/guidance/ng9

6 Lin J, Zhang Y, Xiong L, et al. High-Flow nasal cannula therapy for children with bronchiolitis: a systematic review and meta-analysis. Arch Dis Child 2019;104:564-76.

7 Piper L, Stalets EL, Statile AM. Clinical practice update: high flow nasal cannula therapy for bronchiolitis outside the ICU in infants. $J$ Hosp Med 2019;14:E1-3.

8 Kotecha SJ, Vick D, Delgado-Thompson M, et al. Establishing paediatric ward high-flow nasal cannula usage for infants with bronchiolitis. Acta Paediatr 2020. doi:10.1111/apa.15527. [Epub ahead of print: 08 Aug 2020].

9 Dadlez NM, Esteban-Cruciani N, Khan A, et al. Safety of high-flow nasal cannula outside the ICU for previously healthy children with bronchiolitis. Respir Care 2019;64:1410-5.

10 Sachs N, Rom E, Schonfeld T, et al. Short-Term high-flow nasal cannula for moderate to severe bronchiolitis is effective in a general pediatric ward. Clin Pediatr 2019;58:1522-7.

11 Panciatici M, Fabre C, Tardieu S, et al. Use of high-flow nasal cannula in infants with viral bronchiolitis outside pediatric intensive care units. Eur J Pediatr 2019;178:1479-84.

12 Betters KA, Gillespie SE, Miller J, et al. High flow nasal cannula use outside of the ICU; factors associated with failure. Pediatr Pulmonol 2017;52:806-12.

13 Moreel L, Proesmans M. High flow nasal cannula as respiratory support in treating infant bronchiolitis: a systematic review. Eur $J$ Pediatr 2020;179:711-8.

14 Suzanne M, Amaddeo A, Pin I, et al. Weaning from noninvasive ventilation and high flow nasal cannula in bronchiolitis: a survey of practice. Pediatr Pulmonol 2020;55:3104-9.

15 Korppi M. Weaning off high-flow oxygenation in bronchiolitis. Acta Paediatr 2019;108:2063.

16 Cesar RG, Bispo BRP, Felix PHCA, et al. High-Flow nasal cannula versus continuous positive airway pressure in critical bronchiolitis: a randomized controlled pilot. J Pediatr Intensive Care 2020;9:248-55.

17 Ergul AB, Calıskan E, Samsa H, et al. Using a high-flow nasal cannula provides superior results to OxyMask delivery in moderate to severe bronchiolitis: a randomized controlled study. Eur J Pediatr 2018;177:1299-307.

18 Kepreotes E, Whitehead B, Attia J, et al. High-Flow warm humidified oxygen versus standard low-flow nasal cannula oxygen for moderate bronchiolitis (HFWHO RCT): an open, phase 4, randomised controlled trial. Lancet 2017;389:930-9.

19 Bueno Campaña M, Olivares Ortiz J, Notario Muñoz C, et al. High flow therapy versus hypertonic saline in bronchiolitis: randomised controlled trial. Arch Dis Child 2014;99:511-5.

20 Wan X, Wang W, Liu J, et al. Estimating the sample mean and standard deviation from the sample size, median, range and/or interquartile range. BMC Med Res Methodol 2014:14:135.

21 Abboud P, Roth P, Yacoub N. 702: efficacy of high FLOW/HIGH humidity nasal cannula therapy in viral bronchiolitis. Critical Care Medicine 2015;43:177.

22 Franklin D, Babl FE, Schlapbach LJ, et al. A randomized trial of high-flow oxygen therapy in infants with bronchiolitis. N Engl J Med 2018;378:1121-31.

23 Milési C, Essouri S, Pouyau R, et al. High flow nasal cannula (HFNC) versus nasal continuous positive airway pressure (nCPAP) for the initial respiratory management of acute viral bronchiolitis in young infants: a multicenter randomized controlled trial (TRAMONTANE study). Intensive Care Med 2017;43:209-16.

24 Sarkar M, Sinha R, Roychowdhoury S, et al. Comparative study between noninvasive continuous positive airway pressure and hot humidified high-flow nasal cannulae as a mode of respiratory support in infants with acute bronchiolitis in pediatric intensive care unit of a tertiary care hospital. Indian J Crit Care Med 2018;22:85-90.

25 Hathorn C, Ernst G, Hasan S, et al. S68 the Hi-flo study: a prospective open randomised controlled trial of high flow nasal cannula oxygen therapy against standard care in bronchiolitis. Thorax 2014:69:A38.

26 Mayfield S, Bogossian F, O'Malley L, et al. High-Flow nasal cannula oxygen therapy for infants with bronchiolitis: pilot study. J Paediatr Child Health 2014:50:373-8.

27 Milani GP, Plebani AM, Arturi E, et al. Using a high-flow nasal cannula provided superior results to low-flow oxygen delivery in moderate to severe bronchiolitis. Acta Paediatr 2016;105:e368-72.

28 O'Brien K, Matamoros G, Babbitt C. Does a high-flow nasal cannula weaning protocol for bronchiolitis impact the duration of therapy? critical care medicine. Conference: 48th Critical Care Congress of the Society of Critical Care Medicine, SCCM 2019, United States, 2019.

29 Use of high flow high humidity nasal cannula therapy for infants with bronchiolitis. Journal of Investigative Medicine; 2012. Lippincott Williams \&Amp; Wilkins 530 Walnut ST, Philadelphia, PA 19106-3621 USA.

30 Kefala-Agoropoulou K, Nyamugabo K, Farhat N. High-flow nasal cannula heated-humidified (HFNC) oxygen (O2) at 2 litres (It)/kg/ $\mathrm{min}$ versus low-flow $\mathrm{O} 2$ (up to $2 \mathrm{lt} / \mathrm{min}$ ) in pediatric emergency department (PED) and pediatric ward (PW) in infants with bronchiolitis who need $\mathrm{O} 2$ administration: $\mathrm{A}$ combined prospective randomized controlled and retrospective study: Preliminary results. Eur Respir J 2015;46:PA2173.

31 González Martínez F, González Sánchez MI, Pérez-Moreno J, et al. [What is the optimal flow on starting high-flow oxygen therapy for bronchiolitis treatment in paediatric wards?]. An Pediatr 2019;91:112-9.

32 Milési C, Pierre A-F, Deho A, et al. A multicenter randomized controlled trial of a 3-L/ $\mathrm{kg} / \mathrm{min}$ versus $2-\mathrm{L} / \mathrm{kg} / \mathrm{min}$ high-flow nasal cannula flow rate in young infants with severe viral bronchiolitis (TRAMONTANE 2). Intensive Care Med 2018;44:1870-8.

33 Murphy S, Bruckmann E, Doedens LG, et al. High-Flow oxygen therapy V. standard care in infants with viral bronchiolitis. Southern African Journal of Critical Care 2020;36:110-3.

34 Ramnarayan P, Lister P, Dominguez T, et al. First-Line support for assistance in breathing in children (FIRST-ABC): a multicentre pilot randomised controlled trial of high-flow nasal cannula therapy versus continuous positive airway pressure in paediatric critical care. Crit Care 2018:22:144

35 Yurtseven A, Turan C, Erseven E. Comparison of heated humidified high-flow nasal cannula flow rates $\left(1-\mathrm{L} \cdot \mathrm{kg} \cdot \mathrm{min}^{-1}\right.$ vs $2-\mathrm{L} \cdot \mathrm{kg} \cdot \mathrm{min}$ ${ }^{-1}$ ) in the management of acute bronchiolitis. Pediatr Pulmonol 2019;54:894-900.

36 Chen DY, Zee ED, Gildengorin G, et al. A pilot study of heated and humidified low flow oxygen therapy: an assessment in infants with mild and moderate bronchiolitis (HHOT air study). Pediatr Pulmonol 2019:54:620-7.

37 Durand $\mathrm{P}$, Guiddir T, Kyheng C, et al. A randomised trial of high-flow nasal cannula in infants with moderate bronchiolitis. Eur Respir J 2020;56. doi:10.1183/13993003.01926-2019. [Epub ahead of print: 1607 2020].

38 Ture E, Yazar A, Akn F. High-Flow nasal cannula is superior to standard Face-Mask oxygen therapy in viral bronchiolitis. Signa Vitae 2020;16:47-53.

39 Vahlkvist S, Jürgensen L, la Cour A, et al. High flow nasal cannula and continuous positive airway pressure therapy in treatment of viral bronchiolitis: a randomized clinical trial. Eur $J$ Pediatr 2020:179:513-8.

40 Beggs S, Wong ZH, Kaul S, et al. High-Flow nasal cannula therapy for infants with bronchiolitis. Cochrane Database of Systematic Reviews 2014;97:Cd009609.

41 Moreel L, Proesmans M. High flow nasal cannula as respiratory support in treating infant bronchiolitis: a systematic review. Eur $\mathrm{J}$ Pediatr 2020;179:711-8.

42 Hosheh O, Edwards CT, Ramnarayan P. A nationwide survey on the use of heated humidified high flow oxygen therapy on the paediatric wards in the UK: current practice and research priorities. BMC Pediatr 2020;20:109.

43 Franklin D, Dalziel S, Schlapbach LJ, et al. Early high flow nasal cannula therapy in bronchiolitis, a prospective randomised control trial (protocol): a paediatric acute respiratory intervention study (Paris). BMC Pediatr 2015;15:183.

44 Gc VS, Franklin D, Whitty JA, et al. First-Line oxygen therapy with high-flow in bronchiolitis is not cost saving for the health service. Arch Dis Child 2020;105:975-80.

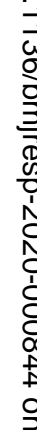

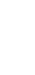

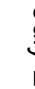

\section{.}

